\title{
Do Practices such as Dowry and Bride Prices relate to Violence Among Migrants in OECD Countries? A Mixed Methods Systematic Review Protocol
}

\author{
Anyier Yuol $^{1 *}$, Nidhi Wali ${ }^{2}$, Shameran Slewa-Younan ${ }^{3}$, Andre M. N. Renzaho ${ }^{1}$ \\ ${ }^{1}$ School of Social Sciences and Psychology, Western Sydney University, Australia \\ ${ }^{2}$ Humanitarian and Development Research Initiative (HADRI), School of Social Sciences and \\ Psychology, Western Sydney University, Australia \\ ${ }^{3}$ School of Medicine, Western Sydney University, Australia
}

\begin{abstract}
This systematic review aims to make a significant contribution to knowledge on dowry and bride price practices in Organisation for Economic Co-operation and Development (OECD) countries, with a focus on Sudan, Zimbabwe and India. While, existing research evidences the ongoing prevalence of dowry and bride price among some migrant communities, there remains substantial gaps in research. The protocol is guided by the Preferred Reporting Items for Systematic Reviews and Meta-Analyses Protocols (PRISMA-P) guidelines. It highlights the scope and methodology for the systematic review to be conducted. Studies will be included if they: (i) were conducted in English; (ii) if they were published between December 1993 and December 2019 because this is the period the dowry-related violence was included into the Declaration on the Elimination of Violence Against Women (iii) used qualitative, quantitative methods or mixed methods; were peer reviewed or grey literature; and (iv) covered analysed dowry and bride price practices and its impact among migrant communities in the OECD countries. Data extraction will be informed by the Joanna Briggs Institute Review for Systematic Reviews and Research Syntheses. The quality of evidence of the studies included will be assessed using the Joanna Briggs Institute tool for qualitative and quantitative studies, the Authority, Accuracy, Coverage, Objectivity, Date, Significance (AACODS) tool for grey literature and the Mixed Methods Appraisal Tool (MMAT) tool for mixed methods studies. Kappa statistics agreement will be used as an additional step to ensure quality ratings are fair and valid. The findings will be summarised into themes and narrated.
\end{abstract}

Systematic review registration: This protocol has been submitted for registration with the international prospective register of systematic reviews and meta-analysis (PROSPERO).

Keywords: Dowry, bride-price, migrants, OECD, low and middle income countries, customs, communities.

\footnotetext{
Correspondence to Anyier Yuol, School of Social Sciences and Psychology, Western Sydney University, Locked Bag 1797, Penrith, NSW 2751, Australia. Email: 18945717@student.westernsydney.edu.au
} 


\section{Background}

There are six forms of marriage payments practiced in many Asian countries, the Middle East and Sub-Saharan Africa (Maitra, 2007). These are: dowry (also known as marriage portion or groom price), brideprice (also known as bridewealth), dower (also termed Bride Gift), brideservice, Bride token, and Gift Exchange/ Sister Exchange (Legal and Constitutional Affairs References Committee, 2019). However, they can be grouped into three broad categories according to the direction of the marriage payments: 1) transfers from the bride's parents to the groom and his family (e.g. dowry), 2) transfers from the groom's parents to the bride and her family (e.g. brideprice, dower, brideservice, and bride Token), or 3) reciprocal exchanges (e.g. Gift Exchange/ Sister Exchange).

Dowry refers to transfers of property, land, money, clothing, household goods, or cattle made to grooms and his family by the bride's parents (Dalmia \& Lawrence, 2005). It is seen as an important responsibility for parents to ensure daughters are given inheritance rights during the time of marriage (Conteh, 2016). Historically, dowry custom was comprehended as an empowerment practice that allowed women to take their own wealth into marriage, therefore be a more equal member of her new family and be less prone to (Indo-Canadian Women's Association, 2019). Unfortunately, the tradition has changed overtime, as many families rely on dowries as a source of income at the time of marriage. Although dowry giving was popular in Europe, East Asia, South Asia, and some parts of the Americas, the custom has largely disappeared in the West (Botticini \& Siow, 2003). In South Asia, the practice remains popular, particularly given the high demand for dowry payments (Arunachalam \& Logan, 2006).

Transfers from the groom's parents to the bride and her family occur in various forms. The bride price refers to transfers of livestock, goods, or money to the bride's family by the groom's parents, (Lacey, 2013). Bride token payment is usually a small symbolic sum. It is often understood as a sign of respect and a token of best wishes for a bride family (Rastogi \& Therly, 2006). In contrast, bride service refers to the service rendered to a bride's family by the groom to validate a marriage (Dean, 2018). It consists of a period of months or years before or after marriage during which the husband performs labour for his wife's parents. The practice of bride service is mostly celebrated in the Amazonia and Central America as an instrument for legitimating marriage (Dean, 2018; Jamieson, 2010). The dower is a common practised in Islamic marriage. The transfer of assets associated with dower is provided to the bride by the groom and his family to insure her against divorce, or to support her in the event that she becomes widowed, or her husband becomes incapacitated (Monsoor, 2003). What distinguishes dower from dowry and bride price is that, it is religiously sanctioned in countries such as Bangladesh (Chowdhury, 2010). Although Islamic law does not specify any maximum amount of dower, the law make it obligatory for a groom to pay whatever amount that has been fixed before or at the time of marriage (Monsoor, 2008).

Lastly, sister exchange payments involve the transfer of a sister or other female relative of the groom to the bride's family in exchange for the bride (Maitra, 2007). This practice was traditionally common in the Lowland of South America and the Northwest of the Amazonia, however it is now practiced in some parts of South Asia, particular in Pakistan and some parts of Punjab in India (Hafeez-ur-Rehman \& Kavesh, 2012; Hugh-Jones, 2013). The tradition of giving bride price is predominately widespread throughout Sub-Saharan Africa, however in some cases, bride price and dowry have co-existed such as in China and Taiwan (Lowes \& Nunn, 2018). In Sub-Saharan Africa, a traditional marriage ceremony depends on payment of a bride price to be valid (Hague, Thiara, \& Turner, 2011). A bride price must be paid first for the couple to get permission to marry. 
Dowry and bride price are the most well-known types of marriage payments in Asian countries and Sub-Saharan Africa (Corno \& Voena, 2016). A number of studies have attempted to explain the occurrence of this prevalent cultural practice and several hypotheses have been put forward to explain dowry and bride price payments. One theory links dowry tradition as a pre mortem bequest and as a rights of inheritance held by women (Botticini \& Siow, 2003). Another theory links marriage payment to the economic value of women, and that it creates an incentive for parents to 'sell' their daughters to obtain the bride price payment (Lowes \& Nunn, 2018). Others argue, in regions where women do not make economic contribution, they are viewed as an economic liability, therefore require a dowry payment as a significant contribution into their new marriage. Additional hypothesis argues that bride price is often interpreted as the purchase of the rights to a woman's labour and reproduction, and rights over a woman's sexuality (Anderson, 2007; Parikh, 2007). While the view of bride price as a purchase of a wife is common, this is very different from the general interpretation of the practice made by anthropologists. For example, Vroklage (1952) ethnographic work on bride price or dower explicitly rejects the idea that a bride price is the price paid for the purchase of a woman, instead describes it as 'a compensation for the expense, the care and trouble spent on the bride's upbringing' (Vroklage, 1952, p. 135). While Vroklage (1952) interpretation of bride price payment is significant in the cultural anthropology perspectives, current studies in contemporary societies have linked marriage payments to the economic value of women (Anderson, 2007).

\section{Migrants with dowry practices moving to OECD countries}

Research reveals that dowry and bride price practices are well alive and evolving among migrant communities in the OECD countries (O'Connor \& Asthana, 2015). The resurgence of dowry and bride price practice in OECD countries can be linked to an emerging and growing problem due to globalisation and increased flows of migration overlapping with marriage (Joppke, 2004; O'Connor \& Asthana, 2015; Walton-Roberts, 2001). In the United States for example, it is observed that migrants from low middle income countries (LMIC) often bring many of their traditional customs with them (Natarajan, 2002). These customs encompass traditional arrangements for marriages, including the dowry and bride price practice. In the Indian community for example, it is documented that young men living in the U.S often go back to India to get married in order to receive a substantial dowry payment (Natarajan, 2002). In other cases, the payment of dowry is secured for migration to other western countries (Mooney, 2006). In contrast, much of the cultural practice observed among subSaharan migrants indicate bride price as a concern among women because the practice often eliminates women voices (Hague et al., 2011). For instance it means that the husband continues to benefit over his wife's body, labour, chores, income, and children she might bring forth (Ting \& Panchanadeswaran, 2009). In other cases, the changing family dynamics amongst sub-Saharan Africa migrants, particularly due to gender role reversals often led to intimate partner violence (IPV) (G. B. Mose \& Gillum, 2016).

Dowry system has become new patterns of household formation and migration into the UK among Indian, Pakistan, Sri Lankan and Bangladesh migrants (Joppke, 2004; Lindley \& Van Hear, 2007). Among these communities parents often import marriage partners for their sons or daughters from the home country and in part, this includes as an exchange for a British visa (Joppke, 2004). As these marriages are often arranged for migration reasons, including financial gain or free domestic labour, many women find themselves suffering and abandoned if they are unwilling or unable to meet the demands of their husbands or in-laws (Patel, Handa, Anitha, \& Jahangir, 2016). This is widely documented in the case of Sri Lankan community where families arrange marriages for either their sons or daughters to

Social Science Protocols, December 2019, 1-13.

http://dx.doi.org/10.7565/ssp.2019.2569 
marry transnationally (Lindley \& Van Hear, 2007). In other cases, it is recognised there is a social pressure on Sri Lankan men to ensure they cover dowry and wedding expenses for their sister's marriage, which may take place transnationally (Lindley \& Van Hear, 2007).

Dowry has also been identified as a migration route for Indian women to Italy (Heim, 2004). It is documented that Indian grooms with Italian citizenship ask families of the bride's to pay high dowry price in order to cover the 'agents' payment for migration (Heim, 2004). This Indian custom is believed to lead to financial exchanges where transnational marriages are arranged for the purpose of migration and economic benefits (Lum, 2012). Further, such as the UK and Italy, dowry custom in France can be an option of obtaining a French nationality, therefore, it is viewed as a great assert for a marriage partner as a form of dowry payment (Bonfanti, 2015). Such exchanges are considered of great value to the Indian national male, who is given the opportunity of gaining French nationality and migrating to France (Joppke, 2004). In such situations, the girl's family does not pay any dowry (Jones, 2009).

In other OECD countries such as Canada and Australia, there is substantial research on dowry demands in the Indian community. For example, Sheel (2005) study shows that reports of cases of deception and mistreatment because of dowry is prevalent in the majority of women who have migrated to Canada under sponsorship of a husband or relative. WaltonRoberts (2001) argues that this practice is not only commonplace but it is also changing the process of migration from India to Canada. There have been cases where transnational marriages among Canadian Indians are viewed as 'selling' of girls, particularly Punjabi women from India (Walton-Roberts, 2004). In other cases, many Punjabi women have been victims of 'fake marriages' where a groom returns to India for marriage, claims dowry and their bride's virginity and returns to Canada with no intention of sponsoring their wives (Walton-Roberts, 2004). These types of practices are modern means of negotiating migration and citizenship rather a marriage (Mooney, 2006).

In the context of Australia, evidence shows dowry and bride price as common practice amongst migrant communities from East Asia, Sub-Saharan Africa and South Asia (Biao, 2005). The practice has been recognised more broadly as a form of economic abuse and highlighted as a contributor of family violence, particularly within the Indian community (Singh \& Sidhu, 2018). For example, some evidence suggests that dowry practice create 'business transaction' where women come to be viewed as commodities (O'Connor \& Asthana, 2015). This type of practice affects family functions, particularly when there is emotional and physical abuse involved (Good Shepherd Australia New Zealand \& inTouch Multicultural Centre Against Family Violence, 2018). On the contrary, while dowry related issues are well documented, the extent of bride price practice among the Sub-Saharan migrant community is limited. Importantly, while current studies address the social changes and economic shift in dowry and bride price practices in OECD countries, little is known about the impact on women, particularly from the sub-Sahara Africa (Anukriti \& Dasgupta, 2017). There is existing social inequality and power imbalance within the Sub-Saharan migrant communities that does not allow women to modify and transform cultural practices (Samuel, 2013). While these obstacles exist, the beliefs and practices of dowry and bride price system is neither uniform nor consistent. For example, in most sub-Saharan Africa the paying of bride price is believed to be symbolising a man's masculinity and role as economic provider as well a recognition of qualities and skills possessed by the bride (Okereke, 2006; Rudwick \& Posel, 2015).

\section{Legal framework in OECD countries and its impact on dowry and bride price}

The extent and the nature of knowledge and understanding regarding dowry and bride price practices is still very new in many OECD countries (Singh \& Sidhu, 2018). Therefore, 
there are not many legal frameworks that address or criminalised dowry practice. However, currently there are international legal instruments that address dowry and bride price issues. For example, Convention on Elimination of all forms of Discriminations Against Women (CEDAW) article 24(3) and article 2(f) refers to dowry related violence as a 'harmful traditional practice because it has been practiced for considerable periods, and abuses have come to be regarded as a part of accepted cultural practice (Convention on the Elimination of All Forms of Discrimination against Women, 1981). Both articles 24(3) and 2(f) provide for appropriate measures including legislation to modify or abolish existing laws, regulations, customs and practices which constitute discrimination against women (CEDAW, 1981). Further, international instrument such as Optional Protocol to the International Covenant on Civil and Political Rights agreed to recognised and consider complaints from individuals who claim their rights under the Covenant have been violated (Mose \& Opsahl, 1981). With respect to national law, India has a national law such as the Dowry Prohibition Act of 1961 that prohibited dowry practice in their country (Banerjee, 2014). India has also enacted amended legislation such as the Dowry Prohibition Amendment Act of 1984 to narrow the loopholes in the Dowry Prohibition Act (1961) and increased the punishment associated with dowry negotiations (Shenk, 2007). Among the OECD countries, Australia has taken the step to address the impact of dowry issues in response to an increase reports of dowry-related abuse. However, Australia does not have a federal law that criminalises the practice of dowry or dowry abuse explicitly (Legal and Constitutional Affairs References Committee, 2019). It is argued that Australia does not require a national anti-dowry law because the existing domestic violence laws are adequate and applicable to the migrant's diaspora living in Australia. Nerveless, the Victorian State Government recently amended the Family Violence Protection Act 2008 to include dowry related abuse (Singh \& Sidhu, 2018). Singh and Sidhu (2018) argue that there is not enough research that shows the prevalence of dowry-related family violence. Singh and Sidhu (2018) have found that while dowry has been overtly being demanded in some cases it is not always a cause of domestic and family violence. Furthermore, countries like Canada have not developed anti-dowry laws because of the Canadian policy of multiculturalism and the protection of the diverse cultural practices brought by immigrants (Sheel, 2005). Additionally, the lack of current research to demonstrate dowry related violence in migrant communities in Canada is not substantial to introduce laws (Sheel, 2005).

\section{Methods/Design}

\subsection{Aims of the review}

This systematic review aims to investigate dowry and bride price practice related to people from the three LMICs of South Sudan, Zimbabwe and India, that have migrated to these top ten OECD countries such as United States, Germany, United Kingdom, Canada, France, Australia, Spain, Italy, Netherlands and Sweden. The selected OECD countries are based on the permanent immigrant inflows (OECD, 2019). LMICs are defined as those with a Gross National Income (GNI) per capital of $\$ 995$ or less or income with a GNI per capital between $\$ 996$ and \$3,895 (Prydz, \& Wadhwa, 2019. These communities have been selected for a number of reasons. Firstly, the South Sudanese community have been selected because they are among Australia's fastest-growing emerging community (Milner, 2010). As has been established, there is little existing research on the impact of bride price on women in this community (Hebbani, Obijiofor, \& Bristed, 2009). Conversely, while substantial research exists on practices in the Indian community, their inclusion is crucial because India is among the top three countries that has a high number of sponsored family category in OECD countries such as Canada, the United States and Australia. For example, as of 2018 Australia

Social Science Protocols, December 2019, 1-13.

http://dx.doi.org/10.7565/ssp.2019.2569 
migration flow from India was $21 \%$, Canada at $18 \%$ and the United States at $5.6 \%$, making India one of the top LMICs to have a high flow of migration into these three countries (OECD, 2018). Thirdly, the Zimbabwe community has been selected because of its similarity of bride price practices to South Sudan. For instance, the payment of bride price is made in order to legalised the marriage in both cultures (Dekker \& Hoogeveen, 2002). Furthermore, it is the groom or the groom's family that pay bride price in Zimbabwean and South Sudanese culture. In addition, this paper will include corresponding examination of the legal framework of dowry practice in South Sudan, with a focus on customary law as there is little existing literature and South Sudan is a new nation.

\section{The review question:}

The systematic review will be guided by the following question: What is the impact of dowry and bride price practices with respect to the related violence among migrants in OECD countries?

\subsection{Study design}

This protocol is guided by the standard Preferred Reporting Items for Systematic Reviews and Meta-Analyses (PRISMA-P) reporting guidelines (Moher et al., 2015). This review will use both qualitative and quantitative evidence of peer review, mixed methods studies and grey literature. To avoid any duplication, Cochrane library, PROSPERO and google scholar were searched to ensure no previous systematic review on dowry and bride price among migrants in OECD countries has been conducted or registered. The following criteria will be used for inclusion:

- Peer reviewed articles, dissertation, books and book chapters, working papers, technical reports, discussion papers published between December 1993 and December 2019.

- Studies are published in English with full texts available and accessible.

- The studies report on or measure dowry related violence and its relationship to the health and well-being of the migrant communities from India, Zimbabwe and South Sudan.

The reference lists of included studies will be scanned for relevant articles that meet the inclusion criteria. The year 1993 has been selected as it was the year that dowry related violence was recognised as a violation of human rights. For example, article 2 of the Declaration on the Elimination of Violence against Women provides that: (a) physical, sexual and psychological violence occurring in the family, including battering, sexual abuse of female children in the household, dowry related violence, marital rape, female genital mutilation, and other traditional practices harmful to women, non-spouse violence and violence related to exploration (General Assembly, 1993). The period also created an awareness for international community to acknowledged that violence against women is an important public health, social policy, and human rights concern (Devries et al., 2013).

\subsection{Participants}

Participants included will be migrants from South Sudan, Zimbabwe and India that have migrated to OECD countries such as Australia, Canada and United States aged 18 years or older, including married or previously married (e.g. given or received dowry or bride price) and never-married. OECD countries are developed countries that have a high-income economy that use their platform to develop best practices on numerous policies, and find answers to common issues (World Population Review, 2019). Migrants are defined as, 
"persons who are living in a country other than their country of birth for reason of migration or legal status" (OECD, 2019).

\subsection{Outcomes of interest}

The outcomes of interest of this review are patterns of dowry and bride price practices and related attitudes, beliefs and violence.

\subsection{Search strategy}

The search will use relevant search terms and sub-heading of key words related to dowry and bride price practices and its impact on migrant communities in OECD countries. Truncations (*), and Boolean operators will be utilised depending on the specifications of databases searched. Various databases for peer-reviewed and grey literature will be searched using subject heading and the following key words.

(Dowry OR "bride price" OR "bride wealth" OR marriage)

AND

(Trends OR practice OR "related violence")

AND

(OECD OR "high income countries" OR Canada OR "United States of America" OR USA OR Australia OR United Kingdom OR UK OR Germany OR France OR Spain OR Italy OR Sweden OR Netherlands)

AND

(Migrant* OR refugee* OR immigrants OR “asylum seeker" OR India OR "South Asia” OR "South Sudan" Or "South Sudanese” OR Zimbabwe* OR "Sub-Saharan Africa)

A comprehensive search of five databases will be conducted. These will include Scopus, JSTOR, ProQuest Central, Social Science Database and Social Sciences Citation Index [via Web of Science]. In addition, grey literature will be sourced from key organisations' websites such as Indo-Canadian Women's Association, Ayaan Hirsi Ali Foundation (AHA), Good Shepherd Australia New Zealand, Indian Ladies UK, Australian Policy Observatory (APO), The Advocates for Human Rights and Global Citizen.

For the purpose of transparency and accountability, a search log will be kept and constantly updated to ensure that newly published articles are captured.

\section{Data collection}

Information recorded will be extracted and imported into an Endnote library and duplicates removed by one independent reviewer (AY). A three staged screening process will be followed. Firstly, studies will be screened to eliminate duplicates. Secondly, titles and abstracts will be screened for eligibility and relevance. Finally, full texts of selected abstracts from the second screening stage will be further reviewed for eligibility. Data collection will be independently carried out by two authors (AY and NW). In cases where there is disagreement or uncertainty, a third reviewer will be consulted to confirm eligibility.

\subsection{Data extraction}

Data extraction sheet will be adapted from Joanna Briggs Institute Review for Systematic Reviews and Research Syntheses (Aromataris \& Munn, 2017). The data to be extracted will include author, country of study, year of publication, study objectives, design and settings, sampling and data collection methods, theory, comments section and patterns of dowry and bride price practices and related attitudes in OECD countries.

Social Science Protocols, December 2019, 1-13.

http://dx.doi.org/10.7565/ssp.2019.2569 


\subsection{Quality assessment}

Joanna Briggs Institute's critical appraisal tools will be adopted for qualitative and quantitative studies (Aromataris \& Munn, 2017). For unpublished grey literature, Authority, Accuracy, Coverage, Objectivity, Date, Significance tool (AACODS) will be considered (Tyndall, 2010). Mixed methods will be evaluated based on Mixed Method Appraisal Tool (MMAT) by McGill Department of Family Medicine (Hong et al., 2018). The quality assessment will be appraised by two researchers (AY and NW) to assess the appropriateness of study aims, methods, objectives and outcomes. Any disagreement will be resolved through discussion with the third reviewer. Agreement between the two assessors will be checked using Cohen's kappa statistics (McHugh, 2012).

\subsection{Data analysis}

While undertaking a preliminary search of literature we anticipate heterogeneity and variation in the study methods. For this reason, a narrative synthesis based on tables of ratings and frequencies is deemed appropriate. Common threads and trends will be identified and extracted from both qualitative and quantitative narratives to generate insight on patterns of dowry and bride price practices related attitudes, beliefs and violence among migrants in the top ten OECD countries. In order to increase transparency of our methods and the conclusions drawn from the studies, the "Improving Conduct and reporting of Narrative Synthesis of Quantitative Data" protocol for mixed methods studies will be used (Campbell, Katikireddi, Sowden, McKenzie, \& Thomson, 2018). All studies results will be aggregated to provide a holistic analysis. However, conclusion will be based on the studies scoring high on quality. AY will summarise the study findings and narrate the emerging themes.

\section{Discussion}

This paper seeks to address a gap in current literature and examines dowry and bride price practice in OECD countries. It will discuss the impact of dowry and bride price practices among migrant's communities from India, Zimbabwe and South Sudan. This study is needed because there is increasing interest around dowry and bride price trends, the attitudes, beliefs, and perceptions among migrants in OECD countries as result of incidents related to dowry abuse among some communities. Despite the attempt to address dowry factors in the current literature, many have failed to recognise the different circumstances in which dowry practice occur amongst South Asian and African communities. Currently, literature postulates that dowry contributes significantly to family domestic violence (Anitha, Yalamarty, \& Roy, 2018). For example, in Australia, research shows that dowry has become a problem among many ethnic communities (O'Connor \& Colucci, 2016). Most of the finding argue that dowry creates demands, financial instability, and family domestic violence (Begum, 2014). Further, women are particularly marginalised as they face obstacles which impose limitations due to dowry's payment. The gap in law and policies surrounding dowry and bride price customs requires greater articulation in OECD countries. For example, the difficulty of defining 'dowry' and 'bride price' makes it challenging to address dowry or criminalise those who practice it (Good Shepherd Australia New Zealand, 2018). In the case of South Sudanese community in Australia it would be difficult to abolish the practice because inherently the practice is seen as a way for the husband to pay his wife's family for values and services she provided to her family (Juuk, 2013). In addition, human rights organisations and the United Nations also view dowry as a practice that overpowers women and places their rights into the hands of their husbands and underlines the status of women within customary marriages (Okereke, 2006). As such, dowry and bride price do not seem to be a disappearing tradition,

Social Science Protocols, December 2019, 1-13. 
rather are expanding with the increase in migration to OECD countries (Srinivasan \& Lee, 2004). Findings from this review can be used to inform the Sustainable Development Goal 5 (SDG 5) towards eliminating all forms of violence and discrimination against all women and girls (García-Moreno et al., 2015). They will also appraise OECD countries such as Canada, the United States and Australia on the effect of dowry and bride price practices among migrants from India, Zimbabwe and South Sudan that impact women's vulnerability. And foremost, to inform existing legal frameworks in addressing dowry and bride prices within OECD countries to eliminate any negative practices.

\subsection{Study limitations}

We anticipated some limitations, such as exclusion of studies published in other languages than English. Exclusion of such studies might lead to missing key literature published by non-English-speaking researchers, especially those who might have a unique interest on the subject. Despite this limitation, the review will explore a range of literature including grey literature to capture and include as many studies as possible to overcome any possible limitation.

\section{List of Abbreviations}

AACODS Authority, Accuracy, Coverage, Objectivity, Date, Significance

AHA Ayaan Hirsi Ali Foundation

APO Australian policy observatory

CEDAW Convention on Elimination of all forms of Discriminations Against Women

ICWA Indo-Canadian Women's Association

LMICs Low and Middle Income Countries

MMAT Mixed methods appraisal Tool

OECD Organisation for Economic Co-operation and Development

PRISMA-P Preferred Reporting Items for Systematic Reviews and Meta-Analyses

PROSPERO International Prospective Register of Systematic Reviews

\section{Declarations}

Ethics approval and consent to participate: Not applicable

Consent for publication: Not applicable

Availability of data and material: Not applicable

Competing interests: The authors declare that they have no competing interests.

Funding: Scholarship has been received for this systematic review from Western Sydney University Postgraduate Research.

Acknowledgements: Not applicable

Start and completion dates: June 2019 - March 2020

\section{References}

Anderson, S. (2007). The economics of dowry and brideprice. Journal of Economic Perspectives, 21(4), 151-174. https://doi.org/10.1257/jep.21.4.151

Social Science Protocols, December 2019, 1-13.

http://dx.doi.org/10.7565/ssp.2019.2569 
Anitha, S., Yalamarty, H., \& Roy, A. (2018). Changing nature and emerging patterns of domestic violence in global contexts: Dowry abuse and the transnational abandonment of wives in India. Women's Studies International Forum, 69, 67-75. https://doi.org/10.1016/j.wsif.2018.05.005

Anukriti, S., \& Dasgupta, S. (2017). Marriage markets in developing countries (IZA Discussion Paper No. 10556). Retrieved from http://ftp.iza.org/dp10556.pdf

Aromataris, E., \& Munn, Z. (2017). JBI systematic reviews. In E. Aromataris \& Z. Munn (Eds.), Joanna Briggs Institute Reviewer's Manual (4th ed.). Retrieved from https://wiki.joannabriggs.org/display/MANUAL/Chapter+1\%3A+JBI+Systematic+Revie Ws

Arunachalam, R., \& Logan, T. D. (2006). On the heterogeneity of dowry motives (NBER Working Paper No. 12630). Retrieved from https://www.nber.org/papers/w12630.pdf

Banerjee, P. R. (2014). Dowry in 21st-century India: The sociocultural face of exploitation. Trauma, Violence, Abuse, 15(1), 34-40. https://doi.org/10.1177/1524838013496334

Begum, A. (2014). Dowry in Bangladesh: A search from an international perspective for an effective legal approach to mitigate women's experiences. Journal of International Women's Studies, 15(2), 249-267.

Biao, X. (2005). Gender, dowry and the migration system of Indian information technology professionals. Indian Journal of Gender Studies, 12(2-3), 357-380. https://doi.org/10.1177/097152150501200209

Bonfanti, S. (2015). The "marriage market" among Punjabi migrant families in Italy: Designs, resistances, and gateways. Human Affairs, 25(1), 16-27. https://doi.org/10.1515/humaff-2015-0002

Botticini, M., \& Siow, A. (2003). Why dowries? American Economic Review, 93(4), 13851398. https://doi.org/ 10.1257/000282803769206368

Campbell, M., Katikireddi, S. V., Sowden, A., McKenzie, J. E., \& Thomson, H. (2018). Improving conduct and reporting of narrative synthesis of quantitative data (ICONSQuant): Protocol for a mixed methods study to develop a reporting guideline. BMJ Open, 8(2), e020064. https://doi.org/10.1136/bmjopen-2017-020064

Chowdhury, F. D. (2010). Dowry, women, and law in Bangladesh. International Journal of Law, Policy and the Family, 24(2), 198-221. https://doi.org/10.1093/lawfam/ebq003

Conteh, J. A. (2016). Dowry and bride-price. In N. Naples, R. C. Hoogland, M. Wickramasing, \& W. C. A. Wong (Eds.), The Wiley Blackwell encyclopedia of gender and sexuality studies (pp. 1-4). Fairborn, OH: Wiley-Blackwell. https://doi.org/10.1002/9781118663219.wbegss548

Corno, L., \& Voena, A. (2016). Selling daughters: Age of marriage, income shocks and the bride price tradition (IFS Working Paper No. W16/08). https://doi.org/10.1920/wp.ifs.2016.1608

Convention on the Elimination of All Forms of Discrimination against Women. (1981). 1249, U.N.T.S. 12. Retrieved from https://www.ohchr.org/documents/professionalinterest/cedaw.pdf

Dalmia, S., \& Lawrence, P. G. (2005). The institution of dowry in India: Why it continues to prevail. The Journal of Developing Areas, 38(2), 71-93. https://doi.org/10.1353/jda.2005.0018

Dean, B. (2018). Bride service. In H. Callan (Ed.), The international encyclopedia of anthropology (pp. 1-2). Lawrence, KS: John Wiley \& Sons. https://doi.org/10.1002/9781118924396.wbiea1440

Dekker, M., \& Hoogeveen, H. (2002). Bride wealth and household security in rural Zimbabwe. Journal of African Economies, 11(1), 114-145. https://doi.org/10.1093/jae/11.1.114

Social Science Protocols, December 2019, 1-13.

http://dx.doi.org/10.7565/ssp.2019.2569 
Devries, K. M., Mak, J. Y. T., Garcia-Moreno, C., Petzold, M., Child, J. C., Falder, G., . . Watts, C. H. (2013). The global prevalence of intimate partner violence against women. Science, 340(6140), 1527-1528. https://doi.org/10.1126/science.1240937

García-Moreno, C., Zimmerman, C., Morris-Gehring, A., Heise, L., Amin, A., Abrahams, N., ... Watts, C. (2015). Addressing violence against women: A call to action. The Lancet, 385(9978), 1685-1695. https://doi.org/10.1016/S0140-6736(14)61830-4

General Assembly. (1993). Declaration on the elimination of violence against women. Retrieved from https://www.ohchr.org/Documents/ProfessionalInterest/eliminationvaw.pdf

Good Shepherd Australia New Zealand, \& inTouch Multicultural Centre Against Family Violence. (2018). The practice of dowry and the incidence of dowry abuse in Australia. Retrieved from https://intouch.org.au/wp-content/uploads/2018/11/inTouch-DowryAbuse-Inquiry-2018.pdf

Hafeez-ur-Rehman, \& Kavesh, M. A. (2012). On exchange marriage: "Wata sata" marriages in southern Punjab, Pakistan. Indian Anthropologist, 42(2), 35-50.

Hague, G., Thiara, R. K., \& Turner, A. (2011). Bride-price and its links to domestic violence and poverty in Uganda: A participatory action research study. Women's Studies International Forum, 34(6), 550-561. https://doi.org/10.1016/j.wsif.2011.06.008

Hebbani, A., Obijiofor, L., \& Bristed, H. (2009). Generational differences faced by Sudanese refugee women settling in Australia. Intercultural Communication Studies, 18(1), 66-82.

Heim, M. (2004). Theories of the gift in South Asia: Hindu, Buddhist, and Jain reflections on dana. New York, NY: Routledge.

Hong, Q. N., Pluye, P., Fàbregues, S., Bartlett, G., Boardman, F., Cargo, M., . . O'Cathain, A. (2018). Mixed Methods Appraisal Tool (MMAT) version 2018 [Measurement instrument]. Retrieved from http://mixedmethodsappraisaltoolpublic.pbworks.com/w/file/fetch/127916259/MMAT_20 18_criteria-manual_2018-08-01_ENG.pdf

Hugh-Jones, S. (2013). Bride-service and the absent gift. Journal of the Royal Anthropological Institute, 19(2), 356-377. https://doi.org/10.1111/1467-9655.12037

Indo-Canadian Women's Association. (n.d.). Dowry. Retrieved October 1, 2019, from https://www.icwaedmonton.org/index.php/violence-against-women/dowry

Jamieson, M. (2010). Mother scorpion: Women's politics and affinal relations among the Miskitu and other "brideservice societies". History and Anthropology, 21(2), 173-189. https://doi.org/org/10.1080/02757206.2010.482753

Jones, G. W. (2009). Indian overseas migration, marriage markets and citizenship issues (IMDS Working Paper No. 9). Retrieved from http://lib.jnu.ac.in/sites/default/files/pdf/imds_p/IMDS_May_2009_WP_9.pdf

Joppke, C. (2004). The retreat of multiculturalism in the liberal state: Theory and policy. The British Journal of Sociology, 55(2), 237-257. https://doi.org/10.1111/j.14684446.2004.00017.x

Juuk, B. (2013). South Sudanese Dinka customary law in comparison with Australian family law: Legal implications for Dinka families. Australasian Review of African Studies, 34(2), 99-112.

Lacey, L. (2013). Women for cows: An analysis of abductions of women in South Sudan. Agenda, 27(4), 91-108. https://doi.org/10.1080/10130950.2013.861685

Legal and Constitutional Affairs References Committee. (2019). The practice of dowry and the incidence of dowry abuse in Australia. Retrieved from https://www.aph.gov.au/Parliamentary_Business/Committees/Senate/Legal_and_Constitut ional_Affairs/DowryAbuse/Report

Social Science Protocols, December 2019, 1-13.

http://dx.doi.org/10.7565/ssp.2019.2569 
Lindley, A., \& Van Hear, N. (2007). New Europeans on the move: A preliminary review of the onward migration of refugees within the European Union (Working Paper No. 57). Retrieved from https://eprints.soas.ac.uk/7474/1/Lindley_NewEuropeanOnTheMove.pdf

Lowes, S., \& Nunn, N. (2018). Bride price and the wellbeing of women. In S. Anderson, L. Beaman, \& J.-P. Platteau (Eds.), Towards gender equity in development (pp. 117-138). Oxford, UK: Oxford University Press. https://doi.org/10.1080/10130950.2013.861685

Lum, K. (2012). Indian diversities in Italy: Italian case study (CARIM-India Research Report No. 2012/02). Retrieved from https://cadmus.eui.eu/bitstream/handle/1814/20821/Carim_India_RR_2012_02_Lum.pdf? sequence $=3$

Maitra, S. (2008). Dowry and bride price. In W. A. Jr. Darity et al. (Eds.), International encyclopedia of the social sciences (2 ed., Vol. 2, pp. 440-442). Detroit, MI: Gale.

McHugh, M. L. (2012). Interrater reliability: The kappa statistic. Biochemia Medica, 22(3), 276-282. https://doi.org/10.11613/BM.2012.031

Milner, K., \& Khawaja, N. G. (2010). Sudanese refugees in Australia: The impact of acculturation stress. Journal of Pacific Rim Psychology, 4(1), 19-29. https://doi.org/10.1375/prp.4.1.19

Moher, D., Shamseer, L., Clarke, M., Ghersi, D., Liberati, A., Petticrew, M., . . . Stewart, L. A. (2015). Preferred Reporting Items for Systematic Review and Meta-analysis Protocols (PRISMA-P) 2015 statement. Systematic Reviews, 4(1), 1-9. https://doi.org/10.1186/2046-4053-4-1

Monsoor, T. (2003, July 27). Dower and dowry: Its effect on the empowerment of Muslim women. The Daily Star. Retrieved from https://www.thedailystar.net/law/200307/04/index.htm

Monsoor, T. (2008). Gender equity and economic empowerment: Family law and women in Bangladesh. Dhaka, Bangladesh: British Council \& EWLR.

Mooney, N. (2006). Aspiration, reunification and gender transformation in Jat Sikh marriages from India to Canada. Global Networks, 6(4), 389-403. https://doi.org/10.1111/j.14710374.2006.00151.x

Mose, E., \& Opsahl, T. (1981). The optional protocol to the international covenant on civil and political rights. Santa Clara Law Review, 21(2), 271-332.

Mose, G. B., \& Gillum, T. L. (2016). Intimate partner violence in African immigrant communities in the United States: Reflections from the IDVAAC African women's round table on domestic violence. Journal of Aggression, Maltreatment Trauma, 25(1), 50-62. https://doi.org/10.1080/10926771.2016.1090517

Natarajan, M. (2002). Domestic violence among immigrants from India: What we need to know and what we should do. International Journal of Comparative and Applied Criminal Justice, 26(2), 301-321. https://doi.org/10.1080/01924036.2002.9678693

O'Connor, M., \& Asthana, M. S. (2015). Refusal to comply with dowry demands contributes to family violence and death in Victoria. Retrieved from Australasian Centre for Human Rights and Health website: http://achrh.org/wp-content/uploads/2016/07/ACHRHSUBMISSION-TO-ROYAL-COMMSSION-ON-DOWRY-RELATED-FAMILYVIOLENCE-AND-DEATH-11-May-2015.pdf

O'Connor, M., \& Colucci, E. (2016). Exploring domestic violence and social distress in Australian-Indian migrants through community theater. Transcultural Psychiatry, 53(1), 24-44. https://doi.org/10.1177/1363461515599327

OECD. (2018). International Migration Outlook 2018. Paris, France: Author. https://doi.org/10.1787/migr_outlook-2018-en

OECD. (2019). Permanent immigrant inflows [Data set]. https://doi.org/10.1787/304546b6en

Social Science Protocols, December 2019, 1-13.

http://dx.doi.org/10.7565/ssp.2019.2569 
Okereke, G. O. (2006). Violence against women in Africa. African Journal of Criminology and Justice Studies, 2(1), 1-35.

Parikh, S. A. (2007). The political economy of marriage and HIV: The ABC approach,"safe" infidelity, and managing moral risk in Uganda. American Journal of Public Health, 97(7), 1198-1208. https://doi.org/10.2105/AJPH.2006.088682

Patel, P., Handa, R., Anitha, S., \& Jahangir, S. (2016). Emerging issues for international family law. Part 3: Transnational marriage abandonment and the dowry question. Family Law Journal, 46(12), 1443-1449. Retrieved from http://eprints.lincoln.ac.uk/

Prydz, E. B., \& Wadhwa, D. (2019). Classifying countries by income. Retrieved from https://datatopics.worldbank.org/world-development-indicators/stories/the-classificationof-countries-by-income.html

Rastogi, M., \& Therly, P. (2006). Dowry and its link to violence against women in India: Feminist psychological perspectives. Trauma, Violence, \& Abuse, 7(1), 66-77. https://doi.org/10.1177/1524838005283927

Rudwick, S., \& Posel, D. (2015). Zulu bridewealth (ilobolo) and womanhood in South Africa. Social Dynamics, 41(2), 289-306. https://doi.org/10.1080/02533952.2015.1060683

Samuel, L. (2013). South Asian women in the diaspora: Reflections on arranged marriage and dowry among the Syrian Orthodox community in Canada. South Asian Diaspora, 5(1), 91105. https://doi.org/10.1080/19438192.2013.722384

Sheel, R. (2005). Marriage, money and gender: A case study of the migrant Indian community in Canada. Indian Journal of Gender Studies, 12(2-3), 335-356. https://doi.org/10.1177/097152150501200208

Shenk, M. K. (2007). Dowry and public policy in contemporary India. Human Nature, 18(3), 242-263. https://doi.org/10.1007/s12110-007-9006-0

Singh, S., \& Sidhu, J. (2018). Coercive control of money, dowry and remittances among Indian migrant women in Australia. South Asian Diaspora, 1-16. https://doi.org/10.1080/19438192.2019.1558757

Srinivasan, P., \& Lee, G. R. (2004). The dowry system in northern India: Women's attitudes and social change. Journal of Marriage and Family, 66(5), 1108-1117. https://doi.org/10.1111/j.0022-2445.2004.00081.x

Ting, L., \& Panchanadeswaran, S. (2009). Barriers to help-seeking among immigrant African women survivors of partner abuse: Listening to women's own voices. Journal of Aggression, Maltreatment and Trauma, 18(8), 817-838. https://doi.org/10.1080/10926770903291795

Tyndall, J. (2010). AACODS checklist. Retrieved from Flinders University website: https://dspace.flinders.edu.au/xmlui/bitstream/handle/2328/3326/AACODS_Checklist.pdf ?sequence $=4 \&$ is Allowed $=\mathrm{y}$

Vroklage, B. (1952). Bride price or dower. Anthropos, 47(1/2), 133-146.

Walton-Roberts, M. (2001). Embodied global flows: Immigration and transnational networks between British Columbia, Canada, and Punjab, India (Doctoral thesis, University of British Columbia, Canada). Retrieved from http://hdl.handle.net/2429/13825

Walton-Roberts, M. (2004). Transnational migration theory in population geography: Gendered practices in networks linking Canada and India. Population, Space and Place, 10(5), 361-373. https://doi.org/10.1002/psp.343

World Population Review. (2019). OECD Countries 2019. Retrieved October 3, 2019, from http://worldpopulationreview.com/countries/oecd-countries/ 